\title{
Increased Exhaled Nitric Oxide Levels Following Exercise in Patients with Chronic Systolic Heart Failure with Pulmonary Venous Hypertension
}

\author{
Andres Schuster, MD1, Akanksha Thakur, MD, Zeneng Wang, $\mathrm{PhD}^{2}$, Allen G. Borowski, \\ RDCS $^{1}$, James D. Thomas, MD ${ }^{1}$, and W. H. Wilson Tang, MD ${ }^{1,2}$ \\ ${ }^{1}$ Department of Cardiovascular Medicine, Heart and Vascular Institute and Department of Cell \\ Biology, Lerner Research Institute, Cleveland Clinic, Cleveland $\mathrm{OH}$ \\ ${ }^{2}$ Stanford University Medical Center, Stanford CA
}

\section{Abstract}

Background-Fractional exhaled nitric oxide (eNO) is recognized as a marker of pulmonary endothelial function. Oxidative stress is associated to systemic endothelial nitric oxide production but its correlation with eNO in heart failure (HF) patients has not been described. Previous studies have reported increased eNO levels after exercise in symptomatic HF patients but decreased levels in pulmonary arterial hypertension. Our objective is to prospectively examine the potential myocardial and functional determinants of exercise-induced rise of eNO in HF.

Methods and Results-Thirty-four consecutive ambulatory patients with chronic systolic HF (left ventricular ejection fraction [LVEF] $\$ 45 \%$ ) underwent symptom-limited cardiopulmonary stress testing and echocardiography. eNO was determined immediately after exercise. Systemic endothelial dysfunction was assessed by asymmetric dimethylarginine (ADMA) and the Larginine/ADMA ratio. In our study cohort (mean age $53 \pm 13$ years, $76 \%$ male, median LVEF $31 \%$, interquartile range [IQR]: 25 to 40 ), the mean eNO was $23 \pm 9 \mathrm{ppb}$. eNO levels were higher in patients with diastolic dysfunction stages 2 or 3 than stage 1 or normal diastology ( $26.1 \pm 9$ vs. $19.5 \pm 7 \mathrm{ppb}, \mathrm{p}=0.013)$. eNO had a positive correlation with estimated systolic pulmonary artery pressure $(\mathrm{r}=0.57 ; \mathrm{p}=0.0009)$ and indexed left atrium volume $(\mathrm{r}=0.43 ; \mathrm{p}=0.014)$, but did not correlate with cardiopulmonary exercise test parameters, ADMA, or symptom score.

Conclusions-In contrast to prior reports, the increase in post-exercise eNO observed in stable chronic systolic HF patients may be attributed to the presence of underlying pulmonary venous hypertension probably secondary to advanced diastolic dysfunction.

\section{Keywords}

Exhaled nitric oxide; congestive heart failure; pulmonary hypertension; echocardiography; asymmetric dimethylarginine

(C) 2012 Elsevier Inc. All rights reserved.

Address for Correspondence: W. H. Wilson Tang, MD, 9500 Euclid Avenue, J3-4, Cleveland, OH 44195., Phone: (216) 444-2121, Fax: (216) 445-6165, tangw@ccf.org.

Disclosure

Dr. Tang reports having received research grant support from Abbott Laboratories, Inc.

Publisher's Disclaimer: This is a PDF file of an unedited manuscript that has been accepted for publication. As a service to our customers we are providing this early version of the manuscript. The manuscript will undergo copyediting, typesetting, and review of the resulting proof before it is published in its final citable form. Please note that during the production process errors may be discovered which could affect the content, and all legal disclaimers that apply to the journal pertain. 


\section{INTRODUCTION}

It has long been recognized that nitric oxide (NO) plays an important role in the pathogenesis and disease progression in heart failure, although direct measurements of NO is challenging and the precise role of NO is complex ${ }^{1}$. In patients with chronic heart failure, dysregulated systemic NO production via endogenous inhibitors of NO synthases like asymmetric dimethylarginine (ADMA), has been associated with both systolic and diastolic dysfunction as well as poor long-term adverse outcomes ${ }^{2}$. Inability to provide substrate for NO production due to impaired global arginine bioavailability has also been associated with increased cardiovascular risks ${ }^{3}$. This is in part due to the fact that vasodilatation in the vasculature is mediated by a basal release of endothelium derived NO. In the lungs, NO plays a crucial role in determining outcomes in airway inflammation, chronic lung diseases, infections and pulmonary arterial hypertension $(\mathrm{PAH})^{4}$. Three forms of NO synthases (endothelial, inducible and neurogenic) are expressed in the lung and respond to a variety of inflammatory cytokines and hemodynamic changes. They are responsible for the synthesis of NO measured in exhaled breath, which derives from vascular endothelium and airway epithelium ${ }^{5}$. Consequentially, exhaled $\mathrm{NO}(\mathrm{eNO})$ has become a promising alternative for indirect in vivo measurement of pulmonary endothelial function.

Over the past decade, studies have reported variable eNO levels in symptomatic heart failure patients at rest when compared to normal controls. Higher resting levels of eNO were observed in decompensated heart failure compared to that observed in compensated, and resting eNO decreased after lowering of left ventricular filling pressures ${ }^{5}$. On the other hand, higher (rather than lower) eNO levels have been observed following exercise in stable chronic heart failure patients when compared to that of controls ${ }^{6-9}$. Meanwhile, those who fail to raise eNO during exercise were associated with a higher long-term mortality rate ${ }^{10}$, suggesting the potential for the generation of $\mathrm{NO}$ as a compensatory response to increased flow in the pulmonary venous circulation. The observation of higher eNO levels upon exercise in the setting of potentially lower NO systemic synthetic capacity is paradoxical. Hence, the objective of the present study is to investigate the relationships between postexercise eNO levels and degree of severity in clinical and echocardiographic variables in stable, compensated, ambulatory patients with chronic systolic heart failure.

\section{METHODS}

\section{Study population}

We prospectively enrolled 34 consecutive ambulatory subjects seen at the Cleveland Clinic outpatient heart failure clinic with a clinical diagnosis of chronic heart failure and left ventricular ejection fraction of $\$ 45 \%$ by echocardiogram. We excluded subjects with a major cardiovascular event (myocardial infarction, unstable angina, stroke, transient ischemic attack, pulmonary embolism) within 30 days, or those with significant lung diseases including chronic obstructive pulmonary disease, pulmonary fibrosis, pulmonary arterial hypertension, or asthma. We also excluded those who had undergone major surgery, hospitalization or emergency room visits for heart failure exacerbation, or use of inotropic agents within the last month. We also excluded those who were unable or unwilling to consent to all components of the protocol. Written informed consent was obtained from all patients before participation in the study, and the protocol was approved by the Cleveland Clinic Institutional Review Board.

\section{Cardiopulmonary exercise testing and eNO measurement}

After informed consent, all subjects underwent symptom-limited cardiopulmonary stress testing using the modified Naughton protocol, and results were recorded on a Vmax ${ }^{\mathrm{TM}}$ 
Encore Metabolic Cart (CareFusion, San Diego CA). Total exercise duration, peak oxygen consumption (Peak $\left.\mathrm{V}_{\mathrm{O} 2}\right)$, and ventilator efficiency $\left(\mathrm{V}_{\mathrm{E}} / \mathrm{V}_{\mathrm{CO} 2}\right)$ were measured. Post-exercise eNO was determined immediately (within 2 minutes) after cardiopulmonary exercise stress test with single-breath technique using a portable eNO analyzer (NIOX MINOH, Aerocrine $\mathrm{AB}$, Solna, Sweden), in which subjects exhaled against an airflow resistor for 10s at a flow rate of $50 \mathrm{~mL} / \mathrm{s}$. In $50 \%$ (17 out of 34) of subjects, resting eNO was measured. The mean coefficient of variation of the measurement was $2.4 \mathrm{ppb}$ and consistent with published report ${ }^{11}$.

\section{Transthoracic echocardiogram}

All patients underwent comprehensive transthoracic echocardiography evaluation using a Vivid 7 system (GE Vingmed Ultrasound, Horten, Norway). Two-dimensional gray-scale and Doppler imaging was performed in standard parasternal and apical views. Left ventricular ejection fraction, left ventricular end- systolic volume index (LVESVI) plus left atrial volume index (LAVI) were measured using the Simpson's biplane method, and the volumetric variables were indexed to body surface area. Pulsed wave Doppler of the right ventricular (RV) inflow and RV outflow were utilized to calculate right-sided myocardial performance index (or the "Tei index"). Right ventricular systolic pressure (RVSP) was estimated from the Doppler estimated tricuspid valve regurgitant jet velocity using the Bernoulli equation. Diastolic parameters, mitral inflow patterns and quantification of mitral regurgitation were assessed and classified following the American Society of Echocardiography recommendations ${ }^{12,13}$.

\section{Kansas City Cardiomyopathy Questionnaire}

The Kansas City Cardiomyopathy Questionnaire (KCCQ) was administered as a standardized 23-item, self-reporting instrument that quantifies physical function, symptoms (frequency, severity and recent change), social function, self-efficacy and knowledge, and quality of life ${ }^{14}$.

\section{L-arginine and ADMA}

To further address the interaction with endothelial dysfunction related to underlying impaired endothelial NO production, we have added measurements of systemic levels of asymmetric dimethylarginine (ADMA) and the ratio between arginine and ADMA in plasma samples collected at the time of study as previously described ${ }^{3}$.

\section{Statistical Analysis}

Normally distributed echocardiographic variables were expressed as mean $\pm \mathrm{SD}$ and compared using parametric methods (unpaired t-test, chi-square test), whereas non-normally distributed, expressed as median with interquartile range, and compared by non-parametric methods (Wilcoxon rank-sum test). Changes in eNO were compared by paired t-test. Crosssectional correlations between echo parameters, stress test parameters and eNO were calculated using non-parametric Spearman's correlation coefficient. Multivariate analysis to identify independent predictors of eNO was performed using Stepwise Logistic Regression. A $\mathrm{p}$ value $<0.05$ was considered significant. The results were not adjusted for multiple comparisons. Statistical analyses were performed using JMP 9.0 (SAS Institute, Cary, NC). All the authors had full access to all of the data in the study, and take responsibility for the integrity of the data and the accuracy of the data analysis. All authors have read and agree to the manuscript as written. 


\section{RESULTS}

\section{Clinical characteristics}

A total of 34 consecutive subjects were prospectively enrolled. Table 1 illustrates the baseline characteristics of the study population. The mean and median resting eNO were $17.9 \pm 7 \mathrm{ppb}$ and $17 \mathrm{ppb}$, (interquartile range 14 to $22 \mathrm{ppb}$ ), respectively. These values were similar to previously reported values for healthy control subjects using a flow rate of $50 \mathrm{~mL} /$ $\mathrm{s}^{15}$. After exercise, the mean and median eNO were increased to $23 \pm 9 \mathrm{ppb}$ and $19.5 \mathrm{ppb}$ (interquartile range 17 to $32 \mathrm{ppb}$ ), respectively. There was a statistically-significant difference between pre- and post-exercise eNO $(\mathrm{p}=0.0149)$. Baseline eNO predicted peak exercise NO $(r=0.80 \mathrm{p}=0.0013, \mathrm{n}=17)$. There was no difference in the eNO levels between Caucasians and African American patients (mean eNO 24.9 \pm 9.3 ppb vs. $24.2 \pm 7.7 \mathrm{ppb}$, $\mathrm{p}=0.63$ ). Mean ADMA and L-arginine levels were $0.88 \pm 0.22 \mu \mathrm{M}$ and $69.3 \pm 14.6 \mu \mathrm{M}$ respectively. The mean L-arginine/ADMA ratio was $82.7 \pm 24.2$.

\section{Exhaled NO and echocardiographic variables}

Resting eNO did not correlate with any of the echocardiographic parameters. In contrast, post-exercise eNO demonstrated a strong and positive correlation with estimated resting $\operatorname{RVSP}(\mathrm{r}=0.57 ; \mathrm{p}=0.0009)$ and LAVI $(\mathrm{r}=0.43 ; \mathrm{p}=0.014)$. Furthermore, the presence of a pseudonormal pattern (Stage 2) or restrictive filling pattern (Stage 3) was associated with higher mean eNO compared to those with a normal or Stage 1 filling pattern $(26.1 \pm 9$ vs. $19.5 \pm 7 \mathrm{ppb}, \mathrm{p}=0.013)$. Despite a trend in the concordant direction, there was no difference in post-exercise eNO between patients with elevated $(\geq 15$ ) versus normal resting mitral $\mathrm{E} / \mathrm{Ea}$ ( $23.9 \pm 8$ vs. $22.3 \pm 10 \mathrm{ppb}, \mathrm{p}=0.29$ ), and between patients with moderate-severe MR versus mild to absent MR at rest ( $22.8 \pm 7$ vs. $23.1 \pm 10 \mathrm{ppb}, \mathrm{p}=0.76)$. Furthermore, eNO after exercise did not correlate with LV systolic function (LVEF, $r=-0.11 ; p=0.29)$, LV endsystolic volume index $(\mathrm{r}=0.24 ; \mathrm{p}=0.19)$, or right ventricular function (Right Tei index, $\mathrm{r}=0.09, \mathrm{p}=0.62)($ Table 2$)$.

Resting and post-exercise eNO did not correlate with ADMA ( $\mathrm{r}=-0.08 \mathrm{p}=0.74$ and $\mathrm{r}=$ $-0.02 ; \mathrm{p}=0.88$ respectively), L-arginine $(\mathrm{r}=-0.21 \mathrm{p}=0.41$ and $\mathrm{r}=-0.09 ; \mathrm{p}=0.61$ respectively), or $\mathrm{L}$-arginine/ADMA ratio $(\mathrm{r}=-0.03 \mathrm{p}=0.89$ and $\mathrm{r}=-0.02 ; \mathrm{p}=0.89$ respectively). The multivariate analysis using stepwise logistic regression identified RVSP and LAVI as independent predictors for elevated post-exercise eNO after adjusting for age, LVEF, E/average Ea ratio, ADMA and L-arginine/ADMA ratio (Table 2).

\section{Exhaled NO and functional parameters and self-reported symptoms}

Resting and post-exercise eNO did not correlate with peak $\mathrm{VO}_{2}(\mathrm{r}=-0.44 \mathrm{p}=0.08$ and $\mathrm{r}=$ $-0.18 ; \mathrm{p}=0.31$ respectively), $\mathrm{V}_{\mathrm{E}} / \mathrm{V}_{\mathrm{CO} 2}(\mathrm{r}=0.22 \mathrm{p}=0.40$ and $\mathrm{r}=0.17 ; \mathrm{p}=0.33)$, or total exercise duration $(r=-0.46 ; p=0.06$ and $r=-0.15 ; p=0.42)$. Furthermore, there were no associations between resting or post-exercise eNO and KCCQ scores, both composite or by components. Resting and post-exercise eNO demonstrated no correlations with KCCQ total symptom score $(r=0.14 ; p=0.65$ and $r=0.17 ; p=0.36)$. Furthermore, exercise duration also did not correlate with KCCQ total symptom score $(r=0.22 ; \mathrm{p}=0.25)$ (Table 2$)$.

\section{Discussion}

The major findings of this hypothesis-generating, exploratory study are the association between post-exercise (but not resting) eNO with echocardiographic features of pulmonary venous hypertension and the lack of correlation between ADMA and eNO production in a compensated chronic systolic HF population. We hypothesize that NO production in the pulmonary vasculature may provide dilatation and recruitment of the pulmonary capillary 
bed in response to high-flow states such as exercise or intrinsic impedance in the setting of pulmonary venous hypertension. By maintaining low impedance across the pulmonary vascular bed, "forward flow" via effective augmentation in cardiac output can be achieved.

The direct and strongest correlation between post-exercise eNO and estimated RVSP observed in our study is in stark contrast with observations of diminished eNO in patients with $\mathrm{PAH}^{16}$. There are several potential explanations which are likely related to the differences in their disease mechanisms associated to the flow-dependent NO production by endothelial cells. In patients with PAH, the primary lesion is pre-capillary, which results in an underfilled pulmonary capillary and pulmonary venous system resulting in low basal NO production. In contrast, patients with left heart disease usually have elevated left filling pressures that increase pulmonary venous pressures at rest but more importantly, during exercise. This unique relation is supported by the lack of correlation between resting eNO and all echocardiographic estimated parameters of filling pressure observed in our findings. It is conceivable that as a compensatory mechanism to augmented pulmonary venous pressure, increased activity of pulmonary endothelial NO synthases occurs in response to increased laminar shear flow during increased flow in the pulmonary vasculature during exercise ${ }^{17}$. Accordingly, higher eNO may represent a functional compensatory mechanism in response to high-flow states.

It is important to discuss that our findings are seemingly in contrast to observations made almost a decade ago by Hare and colleagues ${ }^{5}$ in a group of 30 compensated and 7 acutely decompensated chronic heart failure patients. They reported an inverse correlation between resting eNO levels and invasive systolic pulmonary arterial pressures, and no correlation in the acutely decompensated group. There are several differences between how our study was conducted compared to the study by Hare et al. First, eNO levels that correlated with echocardiographic parameters were measured at post-exercise in our study rather than at rest. Second, our group utilized the standardized eNO measurement with a steady flow rate $^{18}$, which may also explain the overall lower range of eNO levels reported in their study. Third, the ranges of systolic pulmonary artery pressures measured in the Hare et al. study were quite elevated, indicative of a more advanced heart failure population. Fourth, in their study patients with decompensated HF and elevated left filling pressures showed higher eNO levels than chronic stable HF patients, and the eNO levels reduced following HF treatment. The fact that eNO levels decreased after treatment may be supportive of our presenting hypothesis that eNO production being a compensatory response driven by increased pulmonary venous congestion. In fact, failure to increase eNO during exercise in advanced disease states may also reflect an inability to recruit the capillary bed due increased arterial remodeling, leading to a lower capillary flow and eNO production. This would be consistent with the observation that higher mortality associated with failure to increase eNO during exercise in the setting of congestive $\mathrm{HF}^{10}$.

In contrast to with previous studies that showed an inverse correlation between ADMA and L-arginine levels and systemic NO production, we did not see this correlation with resting or post exercise eNO. Exhaled NO reflects in part the pulmonary endothelial NO production, and its lack of correlation with a known NOS competitive inhibitor like ADMA in a compensated HF population, suggest that pulmonary NOS is less influenced by systemic mediators and is more sensitive to local factors like shear flow forces. Furthermore, we recently reported the presence of higher systolic pulmonary pressures in patients with acutely decompensated HF who had higher ADMA levels and lower L-arginine bioavailability ${ }^{19}$. This finding suggests that decreased L-arginine through higher ADMA levels contribute to the pulmonary vascular tone in this population subset. The interaction between ADMA/L-arginine and local production of NO in the pulmonary bed in patients with acute decompensated HF warrants further investigation. 
Different individuals may be at different disease stages, and the underlying causes of heart failure symptoms or impaired functional capacity may be multifactorial. Hence, the lack of association between exercise-induced eNO and self-reported symptom status as well as cardiopulmonary exercise parameters is not too surprising. In fact, our findings were consistent with prior reports of eNO analyses that indicated lack of correlation between peak oxygen consumption, ventilatory efficiency, and lung function in patients with heart failure ${ }^{6,8,9}$. Unlike in asthma, bronchial hyperresponsiveness is not a predominant feature in non-smoking patients with compensated heart failure, and thus are unlikely to contribute to the elevated eNO levels seen in heart failure ${ }^{20}$. Nevertheless, we found no difference in the eNO levels between the non-smokers and the patients with prior smoking history. Whether enhancing cardiopulmonary NO responses to exercise may serve as a therapeutic strategy to improve clinical outcomes warrants further investigations in this area, as NOdonating drugs have already shown some promising benefits in ambulatory patients with heart failure and hemodynamic derangements ${ }^{21,22}$. There is also a need to better understand the potential for serial monitoring of post-exercise eNO in tracking with another dimension of disease progression.

As previously described, other eNO studies have shown heterogenic results in terms of exhaled NO levels at rest and its changes post exercise. This can probably be explained by the disparity of the populations assessed and the previous use of non-standardized techniques for eNO analysis. Our findings were similar to previous results where eNO levels increased post exercise in chronic HF patients 9 .

\section{Study limitations}

Despite being one of the largest reported series of post-exercise eNO assessment in heart failure, our study is limited by its relatively small number of patients, and the use of multiple comparisons. Also, its cross-sectional design only provides insights in to interrelationships between different physiologic parameters, hence causality cannot be established. In addition, we did not have direct hemodynamic measurements to confirm the presence of pulmonary venous hypertension nor other consistent assessment of endothelial dysfunction, and evaluation of resting eNO occurred only in half of the patients. Further investigations in the clinical significance of measuring post-exercise eNO, and direct comparisons with different measures of endothelial function in patients with heart failure are warranted.

\section{Conclusions}

In this hypothesis-generating exploratory study of stable ambulatory patients with chronic systolic heart failure, the observed increase in post-exercise eNO is associated with echocardiographic evidence of pulmonary venous hypertension secondary to left heart disease.

\section{Acknowledgments}

\section{Funding Sources}

This research was supported by National Institutes of Health grants 1R01HL103931 and the Cleveland Clinic Clinical Research Unit of the Case Western Reserve University CTSA (UL1TR 000439-06), and the American College of Cardiology Foundation.

\section{References}

1. Tousoulis D, Papageorgiou N, Briasoulis A, Androulakis E, Charakida M, Tsiamis E, Stefanadis C. Conflicting effects of nitric oxide and oxidative stress in chronic heart failure: Potential therapeutic strategies. Heart Fail Rev. 2011 
2. Tang WH, Tong W, Shrestha K, Wang Z, Levison BS, Delfraino B, Hu B, Troughton RW, Klein AL, Hazen SL. Differential effects of arginine methylation on diastolic dysfunction and disease progression in patients with chronic systolic heart failure. Eur Heart J. 2008; 29:2506-2513. [PubMed: 18687662]

3. Tang WH, Wang Z, Cho L, Brennan DM, Hazen SL. Diminished global arginine bioavailability and increased arginine catabolism as metabolic profile of increased cardiovascular risk. J Am Coll Cardiol. 2009; 53:2061-2067. [PubMed: 19477356]

4. Rodway GW, Choi J, Hoffman LA, Sethi JM. Exhaled nitric oxide in the diagnosis and management of asthma: Clinical implications. Chron Respir Dis. 2009; 6:19-29. [PubMed: 19176709]

5. Hare JM, Nguyen GC, Massaro AF, Drazen JM, Stevenson LW, Colucci WS, Fang JC, Johnson W, Givertz MM, Lucas C. Exhaled nitric oxide: A marker of pulmonary hemodynamics in heart failure. J Am Coll Cardiol. 2002; 40:1114-1119. [PubMed: 12354437]

6. Agostoni P, Bussotti M. Exhaled nitric oxide and exercise performance in heart failure. Arch Physiol Biochem. 2003; 111:293-296. [PubMed: 15764057]

7. Funakoshi T, Yamabe H, Yokoyama M. Increased exhaled nitric oxide and impaired oxygen uptake (vo2) kinetics during exercise in patients with chronic heart failure. Jpn Circ J. 1999; 63:255-260. [PubMed: 10475772]

8. Lovell SL, Stevenson H, Young IS, McDowell G, McEneaney D, Riley MS, Nicholls DP. Exhaled nitric oxide during incremental and constant workload exercise in chronic cardiac failure. Eur J Clin Invest. 2000; 30:181-187. [PubMed: 10691993]

9. Seshadri N, Dweik RA, Laskowski D, Pothier C, Rodriguez L, Young JB, Migrino RQ. Dysregulation of endogenous carbon monoxide and nitric oxide production in patients with advanced ischemic or nonischemic cardiomyopathy. Am J Cardiol. 2003; 92:820-823. [PubMed: 14516883]

10. Katz SD, Hryniewicz K, Hriljac I, Balidemaj K, Dimayuga C, Hudaihed A, Yasskiy A. Vascular endothelial dysfunction and mortality risk in patients with chronic heart failure. Circulation. 2005; 111:310-314. [PubMed: 15655134]

11. Takalo R, Piirila P, Sovijarvi AR. Repeatability of successive measurements with a portable nitric oxide analyser in patients with suggested or diagnosed asthma. Scand J Clin Lab Invest. 2008; 68:830-832. [PubMed: 19061091]

12. Nagueh SF, Appleton CP, Gillebert TC, Marino PN, Oh JK, Smiseth OA, Waggoner AD, Flachskampf FA, Pellikka PA, Evangelista A. Recommendations for the evaluation of left ventricular diastolic function by echocardiography. J Am Soc Echocardiogr. 2009; 22:107-133. [PubMed: 19187853]

13. Zoghbi WA, Enriquez-Sarano M, Foster E, Grayburn PA, Kraft CD, Levine RA, Nihoyannopoulos P, Otto CM, Quinones MA, Rakowski H, Stewart WJ, Waggoner A, Weissman NJ.

Recommendations for evaluation of the severity of native valvular regurgitation with twodimensional and doppler echocardiography. J Am Soc Echocardiogr. 2003; 16:777-802. [PubMed: 12835667]

14. Green CP, Porter CB, Bresnahan DR, Spertus JA. Development and evaluation of the kansas city cardiomyopathy questionnaire: A new health status measure for heart failure. J Am Coll Cardiol. 2000; 35:1245-1255. [PubMed: 10758967]

15. Kharitonov SA, Gonio F, Kelly C, Meah S, Barnes PJ. Reproducibility of exhaled nitric oxide measurements in healthy and asthmatic adults and children. Eur Respir J. 2003; 21:433-438. [PubMed: 12661997]

16. Girgis RE, Champion HC, Diette GB, Johns RA, Permutt S, Sylvester JT. Decreased exhaled nitric oxide in pulmonary arterial hypertension: Response to bosentan therapy. Am J Respir Crit Care Med. 2005; 172:352-357. [PubMed: 15879413]

17. Noris M, Morigi M, Donadelli R, Aiello S, Foppolo M, Todeschini M, Orisio S, Remuzzi G, Remuzzi A. Nitric oxide synthesis by cultured endothelial cells is modulated by flow conditions. Circ Res. 1995; 76:536-543. [PubMed: 7534657]

18. Grob NM, Dweik RA. Exhaled nitric oxide in asthma: Progress since the introduction of standardized methodology. J Breath Res. 2008; 2:37002. [PubMed: 20664809] 
19. Shao Z, Wang Z, Shrestha K, Thakur A, Borowski AG, Sweet W, Thomas JD, Moravec CS, Hazen SL, Tang WH. Pulmonary hypertension associated with advanced systolic heart failure: Dysregulated arginine metabolism and importance of compensatory dimethylarginine dimethylaminohydrolase-1. J Am Coll Cardiol. 2012; 59:1150-1158. [PubMed: 22440215]

20. Chua TP, Lalloo UG, Worsdell MY, Kharitonov S, Chung KF, Coats AJ. Airway and cough responsiveness and exhaled nitric oxide in non-smoking patients with stable chronic heart failure. Heart. 1996; 76:144-149. [PubMed: 8795478]

21. Mullens W, Abrahams Z, Francis GS, Sokos G, Starling RC, Young JB, Taylor DO, Tang WH. Usefulness of isosorbide dinitrate and hydralazine as add-on therapy in patients discharged for advanced decompensated heart failure. Am J Cardiol. 2009; 103:1113-1119. [PubMed: 19361599]

22. Taylor AL, Ziesche S, Yancy C, Carson P, D'Agostino R Jr, Ferdinand K, Taylor M, Adams K, Sabolinski M, Worcel M, Cohn JN. Combination of isosorbide dinitrate and hydralazine in blacks with heart failure. N Engl J Med. 2004; 351:2049-2057. [PubMed: 15533851] 
Table 1

Baseline characteristics of patients with chronic stable heart failure

\begin{tabular}{|c|c|}
\hline Variable & Value \\
\hline \multicolumn{2}{|l|}{ Demographics: } \\
\hline Mean Age (years) & $53 \pm 13$ \\
\hline Male gender (\%) & 76 \\
\hline African-American (\%) & 15 \\
\hline \multicolumn{2}{|l|}{$\underline{\text { Heart failure etiology and functional class: }}$} \\
\hline Non-ischemic cardiomyopathy (\%) & 55 \\
\hline Chemotherapy-induced (\%) & 10 \\
\hline Valvular disease $(\%)$ & 6 \\
\hline Ischemic etiology (\%) & 29 \\
\hline NYHA Functional Class (I/II/III, \%) & $10 / 70 / 20$ \\
\hline \multicolumn{2}{|l|}{ Exhaled Nitric Oxide (ppb): } \\
\hline Resting & $17(13.5-21.5)$ \\
\hline Post-exercise & $20(17-31)$ \\
\hline \multicolumn{2}{|l|}{ Echocardiographic Data: } \\
\hline LV ejection fraction (\%) & $31(25-40)$ \\
\hline LV end-diastolic dimension $(\mathrm{cm})$ & $6.0 \pm 1.1$ \\
\hline $\mathrm{LV}$ end-systolic volume index $\left(\mathrm{ml} / \mathrm{m}^{2}\right)$ & $60.6(38.6-97.5)$ \\
\hline RV myocardial performance (Tei) index & $0.62 \pm 0.24$ \\
\hline RV systolic pressure $(\mathrm{mmHg})$ & $35(30-42)$ \\
\hline LA volume index $\left(\mathrm{ml} / \mathrm{m}^{2}\right)$ & $31.4(22.7-50.3)$ \\
\hline Mitral E/Average Ea & $9.8(6.7-20.4)$ \\
\hline \multicolumn{2}{|l|}{ Comorbidities: } \\
\hline Diabetes mellitus (\%) & 30 \\
\hline Hypertension (\%) & 53 \\
\hline Hyperlipidemia (\%) & 70 \\
\hline Prior cigarette smoking $(\%)$ & 48 \\
\hline \multicolumn{2}{|l|}{ Medications: } \\
\hline ACE inhibitor/ARBs (\%) & 87 \\
\hline Beta-blockers (\%) & 91 \\
\hline Loop diuretics (\%) & 73 \\
\hline Aldosterone receptor antagonists (\%) & 37 \\
\hline Hydralazine (\%) & 17 \\
\hline Isosorbide dinitrate $(\%)$ & 33 \\
\hline
\end{tabular}

J Card Fail. Author manuscript; available in PMC 2013 October 01. 
Table 2

Association of eNO with echo and exercise stress test parameters

\begin{tabular}{|c|c|c|c|c|}
\hline & \multicolumn{2}{|c|}{ Resting eNO } & \multicolumn{2}{|c|}{ Post-exercise eNO } \\
\hline Variables & Correlation (r) & p value & Correlation (r) & p value \\
\hline \multicolumn{5}{|l|}{ Echocardiographic Variables } \\
\hline RVSP & 0.40 & 0.13 & 0.57 & 0.0009 \\
\hline LAVI & 0.16 & 0.55 & 0.43 & 0.014 \\
\hline LVEF & -0.016 & 0.95 & -0.11 & 0.29 \\
\hline Right Tei index & 0.0049 & 0.98 & 0.09 & 0.62 \\
\hline LVDD & 0.20 & 0.45 & 0.27 & 0.13 \\
\hline LVESVI & -0.052 & 0.84 & 0.24 & 0.19 \\
\hline \multicolumn{5}{|l|}{ ADMA/L-arginine } \\
\hline ADMA & -0.08 & 0.74 & -0.02 & 0.88 \\
\hline L-Arginine & -0.21 & 0.41 & -0.09 & 0.61 \\
\hline L-Arginine/ADMA ratio & -0.03 & 0.89 & -0.02 & 0.89 \\
\hline \multicolumn{5}{|c|}{ Cardiopulmonary Exercise Variables } \\
\hline peak $\mathrm{V}_{\mathrm{O} 2}$ & -0.44 & 0.08 & -0.18 & 0.31 \\
\hline $\mathrm{V}_{\mathrm{E}} / \mathrm{V}_{\mathrm{CO} 2}$ & 0.22 & 0.40 & 0.17 & 0.33 \\
\hline Exercise duration & -0.46 & 0.06 & -0.15 & 0.42 \\
\hline \multicolumn{5}{|l|}{ Clinical Variables } \\
\hline KCCQ Total symptom score & 0.14 & 0.65 & 0.17 & 0.36 \\
\hline
\end{tabular}

Abbreviations: $\mathrm{eNO}=$ exhaled nitric oxide; RVSP = right ventricular systolic pressure; LAVI = left atrial volume index; $\mathrm{LVEF}=$ left ventricular ejection fraction; LVEDD = left ventricular diastolic dimension; LVESVI = left ventricular end-systolic volume index; ADMA = asymmetric dimethylarginine; $\mathrm{VO} 2$ = ventilatory oxygen uptake; $\mathrm{VE} / \mathrm{VCO} 2$ = ventilatory equivalent ratio for carbon dioxide; $\mathrm{KCCQ}=$ Kansas City Cardiomyopathy Questionnaire 